\title{
Low levels of physical activity and metabolic syndrome: cross-sectional study in the Brazilian public health system
}

\author{
Baixos níveis de atividade física e síndrome metabólica: estudo \\ transversal com usuários do sistema público de saúde brasileiro
}

\author{
Bruna Camilo Turi ${ }^{1}$ \\ Jamile Sanches Codogno ${ }^{2}$ \\ Rômulo Araújo Fernandes ${ }^{2}$ \\ Henrique Luiz Monteiro ${ }^{3}$
}

\footnotetext{
${ }^{1}$ Programa de Pós-

Graduação em Ciências da

Motricidade, Universidade Estadual Paulista "Júlio de Mesquita Filho” (UNESP) Avenida 24 A/1515, Bela

Vista. 13506-900 Rio Claro SP Brasil.brunaturi@

hotmail.com

${ }^{2}$ Departamento de

Educação Física, UNESP.

Presidente Prudente SP

Brasil.

${ }^{3}$ Departamento de

Educação Física, UNESP.

Bauru SP Brasil.
}

\begin{abstract}
This study investigated whether low levels of physical activity in different domains is associated with risk factors for the occurrence of metabolic syndrome or metabolic syndrome itself. Habitual physical activity level was assessed among 963 participants, aged 50 years old or more, using Baecke's questionnaire. Risk factors for metabolic syndrome followed the recommendations of "The IDF Consensus Worldwide Definition of the Metabolic Syndrome". All the participants were users of the Brazilian Public Healthcare System. The prevalence of metabolic syndrome was $30.9 \%$. Participants with lower levels of physical activity in leisure-time had higher chances of occurrence of diabetes mellitus, hypercholesterolemia and metabolic syndrome. Occurrence of arterial hypertension was associated with lower levels of sports activities. It was found high rates of risk indicators for the occurrence of metabolic syndrome, as well as for diseases alone as hypertension, diabetes mellitus, hypercholesterolemia, and obesity. Lower involvement in physical activity in different domains increases the prevalence of risk factors for metabolic syndrome.
\end{abstract}

Key words Motor activity, Metabolic Syndrome X, Unified Health System, Epidemiology
Resumo Este estudo investigou se baixos níveis de atividade física em diferentes domínios está associado a fatores de risco para a ocorrência da síndrome metabólica ou a sindrome metabólica em si. Nível de atividade física habitual foi avaliada entre 963 participantes, com idade igual ou superior a 50 anos, usando o questionário de Baecke. Fatores de risco para síndrome metabólica seguiram as recomendações do "The IDF Consensus Worldwide Definition of the Metabolic Syndrome". Todos os participantes eram usuários do sistema público de saúde brasileiro. A prevalência de sindrome metabólica foi de 30.9\%. Participantes com menores níveis de atividade física no lazer tiveram maiores chances de ocorrência de diabetes mellitus, hipercolesterolemia e síndrome metabólica. Ocorrência de hipertensão arterial foi associada com menores níveis de atividades esportivas. Foram encontradas altas taxas de indicadores de risco para a ocorrência da síndrome metabólica, assim como para doenças isoladas, como hipertensão arterial, diabetes mellitus, hipercolesterolemia e obesidade. Menores engajamento com a prática de atividades físicas em diferentes domínios aumenta a prevalência de fatores de risco para a síndrome metabólica.

Palavras-chave Atividade motora, Sindrome $X$ Metabólica, Sistema Único de Saúde, Epidemiologia 


\section{Introduction}

The metabolic syndrome (MetS) is a complex disorder represented by a cluster of metabolic abnormalities that are commonly associated with obesity, high blood pressure, dyslipidemia, hyperglycemia and hyperinsulinemia. Besides being defined by several interconnected factors, MetS increases by two to four times the risk of stroke, three to four times the risk of myocardial infarction, and twice the risk of dying from such an event compared with those without the syndrome ${ }^{1}$. Thus, recognized worldwide as a major public health and clinical problem by increasing risk of chronic diseases ${ }^{2}$, its prevention is considered a fundamental goal of public health.

Global prevalence of MetS varies depending on the region and composition of the population studied $^{3}$. In general, it's estimated that one-quarter of the world's adult population has the MetS ${ }^{4}$. In Brazil, studies have found lower prevalence, but no less alarming, ranging from $6.7 \%^{5}$ and $7.6 \%{ }^{6}$. Thus, prevalence of MetS is different according to regions and populations and also related to several clinical definitions proposed and used in studies worldwide ${ }^{1}$.

Despite being characterized as a multifactorial disease, the main factors for the occurrence of MetS are genetic ${ }^{7}$, inflammatory ${ }^{8}$, dietary patterns and lifestyle ${ }^{9}$, and the last two are potentially modifiable. Compliance with the current recommendations $^{1}$, increasing the total volume of moderate-intensity physical activity and to maintain good cardiorespiratory and muscular fitness appears to markedly decrease the likelihood of developing the MetS, especially in high-risk groups $^{10}$. However, studies on this subject are not well explored in Brazilian population, especially among users of the public healthcare system.

Nevertheless, the aim of this study was to determine whether associations between risk factors for the occurrence of MetS / MetS itself and physical inactivity among adult users of the public healthcare system in Brazil.

\section{Methods}

\section{Sample}

This project was a cross-sectional study conducted from August 2010 to December 2010 in the city of Bauru (the most industrialized region of the country). Prior to implementation the study was approved by the Ethics Committee Group from Universidade Estadual Paulista, Bauru campus (Process number 1046/46/01/10), and all subjects were asked to sign a standard written consent form. The sample size was estimated based on the percentage of Brazilian population that are covered only by the public health system $(60 \%)^{11}$ and using parameters as 3.8\% error (arbitrary because there are no other similar studies), $5 \%$ statistical significance and design effect of $50 \%$. A sample size of 960 participants was estimated to be representative (minimum of 192 in each Basic Healthcare Unit [BHU]). The city was stratified into five geographical regions (south, west, north, east and center) and the major BHU from each geographical region was selected.

As inclusion criteria were defined: i) age $\geq 50$ years; ii) register for at least one year at the BHU; iii) have active registration of healthcare service (have performed at least one medical visit in the past six months). After that, a list with the number of all medical records that reached the inclusion criteria above was made and a random selection was performed until the minimum number of participants is reached. The final sample size was 963 participants.

\section{Risk Factors for Metabolic Syndrome}

MetS was defined as subjects who had presence of any three of the five following risk factors, as defined by Alberti et al. ${ }^{1}:$ i) increased waist circumference [population specific $(80 \mathrm{~cm}$ for women and 94 for men)]; ii) increased triglycerides (> $150 \mathrm{mg} / \mathrm{dL}$ or specific treatment to be performing such abnormality); iii) reduced HDL cholesterol $(<40 \mathrm{mg} / \mathrm{dL}$, or is performing a specific treatment for this abnormality); iv) high blood pressure (systolic blood pressure $>130 \mathrm{mmHg}$ or diastolic blood pressure $>85$ $\mathrm{mmHg}$ or be performing treatment for previously diagnosed arterial hypertension $(\mathrm{AH})$; v) increased fasting glucose (>100 mg / dL or previous diagnosis of diabetes mellitus (DM) type 2).

To check the occurrence of such factors were performed: anthropometric measurements of waist circumference, ii) verification on the results of specific tests (triglycerides, HDL cholesterol and fasting glucose) registered on the medical record of the patient and performed in the 12 months preceding the interview, and finally iii) consultation on any chronic disease diagnosis properly recorded by the physician in the clinical record. 


\section{Habitual Physical Activity}

The level of PA was estimated using the questionnaire developed by Baecke et al. ${ }^{12}$, which considers three domains of PA: Occupational PA, Sport practice, and Leisure-time PA. The PA level is calculated by specific equations and is expressed as a scores for each PA domain (higher score denotes higher PA) and the sum of all domains constitutes the overall PA. The sample was then divided into quartiles within each domain of PA and participants were classified into four groups ${ }^{13}$ : Physically inactive $(\leq \mathrm{P} 25)$, Moderately Active $(<$ P25 and $\geq$ P75) and Active ( $>$ P75).

\section{Potential confounders}

The following data were obtained through interviews and confirmed in medical records: (i) socio-demographic variables (sex, chronological age [structured as categorical variable: $<65$ years-old and $\geq 65$ years-old]); (ii) smoking habits [categorized as "yes" (current smokers independently of number of cigarettes per day) and "no" (former smokers or never smoked)]; (iii) economic status, assessed by a specific and previously validated Brazilian questionnaire ${ }^{14}$, which estimates the family income (dichotomized into either low or high income) and includes the level of formal education; (iv) abdominal obesity, obtained with values of waist circumference $(80 \mathrm{~cm}$ for women and 94 for men $)^{15}$; (v) general obesity [body mass index (BMI)], calculated using measurements of weight and height and obtained by dividing weight by squared height and defined as $\mathrm{BMI} \geq 30 \mathrm{~kg} / \mathrm{m}^{2}{ }^{16}$; (vi) blood pressure was measured in a seated position at rest and values lower than 130/85 $\mathrm{mmHg}$ for systolic (SBP) and diastolic blood pressure (DBP) were considered normal, respectively.

\section{Statistical analyzes}

Categorical variables were expressed as rates and compared by the chi-square test (Yates's correction was applied in $2 \times 2$ contingence tables). Significant associations detected by chi-square test were further analyzed by the binary logistic regression, which generated values of odds ratio (OR) and 95\% confidence intervals (CIs). The association between the occurrence of the diseases and physically inactive domains was simultaneously adjusted by potential confounders (Basic Health Care Units, age, sex, smoking habit, economic condition, increased waist circumfer- ence, overweight, SBP and DBP). In all adjusted multivariable models, after inclusion of potential confounders, the Hosmer-Lemeshow goodness-of-fit test was used to determine how well the model fit the data (non-significant results indicate an adequate adjustment). All statistical analyses were performed by the software BioEstat (release 5.0) and statistical significance (p-value) was set at 0.05 .

\section{Results}

This sample was composed of 963 patients from five BHU in Bauru - SP, being 26.6\% male ( $\mathrm{n}=$ $256)$ and $73.4 \%$ female $(n=707)$. Mean age was $65 \pm 9$ years (ranging from 50 to 96 years old). Regardless of the region of collection, the prevalent economic status in the sample was the low one, comprehending $83.2 \%$ of all of the assessed participants $(\mathrm{n}=801) .13 .2 \%$ of the participants reported to be current smokers $(n=127)$ and $33.7 \%$ were former smokers $(n=325)$. Mean score for occupational PA was $3.56 \pm 1.71$ (ranging from 0.63 to 9.38 ), for sport practice was $1.35 \pm 0.55$ (ranging from 0.75 to 3.82 ) and for leisure time PA was $2.88 \pm 0.76$ (ranging from 1.00 to 4.75 ).

There were high rates of $\mathrm{AH}$ (76.8\% [74.1\% to $79.5 \%])$, DM (28.6\% [25, 7\% to $31.4 \%])$, hypercholesterolemia $(32.7 \%$ [29.7\% to $35.6 \%])$ and abdominal obesity (87.7\% [85.7\% to $89.8 \%])$. The prevalence of MetS was 33.6\% (30.66 to $36.63)$, with no significant difference between different economic status (low income: 33.3\%; high income: $35.2 \%$; $\mathrm{p}$-value $=0.649)$.

Comparing sexes, there were no statistical differences between men and women regarding to all diseases, however, older people (over 65 years-old) had a higher incidence of $\mathrm{AH}$ when compared to younger participants $(81.1 \%$ versus $73,4 \%$, respectively [p-value $=0.006])$; the same pattern was not observed for DM and hypercholesterolemia. On the other hand, participants with overweight / obesity and abdominal obesity had higher occurrence of all diseases analyzed.

Table 1 shows associations between levels of PA in different domains and diseases analyzed. We found that, even after robust adjustment for potential confounders, lower level of PA in leisure-time was significantly associated with a higher prevalence of DM $(\mathrm{OR}=1.82[1.22$ 2.71]) and hypercholesterolemia $(\mathrm{OR}=1.82$ [1.25-2.66]). However, AH was only associated with lower levels of sport practice $(\mathrm{OR}=1.67$ [1.05-2.65]). 
Table 1. Association between physical activity domains and chronic diseases (Brazil, $\mathrm{n}=963$ ).

\begin{tabular}{|c|c|c|c|c|c|c|}
\hline \multirow{2}{*}{ PA Domains } & \multicolumn{2}{|c|}{ Arterial Hypertension } & \multicolumn{2}{|c|}{ Diabetes mellitus } & \multicolumn{2}{|c|}{ Hypercholesterolemia } \\
\hline & $\mathbf{N}(\%)$ & OR $(95 \% C I)$ & $\mathbf{N}(\%)$ & OR $(95 \% C I)$ & $\mathbf{N}(\%)$ & OR $(95 \% C I)$ \\
\hline \multicolumn{7}{|l|}{ Occupational } \\
\hline Physically inactive & $197(82,1)$ & --- & $85(35,4)$ & $1.32(0.84-2.08)$ & $69(28,8)$ & --- \\
\hline Moderately Active & $353(73,4)$ & --- & $124(25,8)$ & $0.90(0.62-1.30)$ & $171(35,6)$ & --- \\
\hline Active & $\begin{array}{c}190(78,5) \\
\text { p-value }=0,357\end{array}$ & --- & $\begin{array}{c}66(27,3) \\
\text { p-value }=0,049\end{array}$ & $\begin{array}{c}1.00 \\
\text { p-value }=0,390^{*} \\
(71,1 \%)^{* *}\end{array}$ & $\begin{array}{c}75(31) \\
\text { p-value }=0,604\end{array}$ & --- \\
\hline \multicolumn{7}{|l|}{ Sports } \\
\hline Physically inactive & $194(79,8)$ & $1.67(1.05-2.65)$ & $79(32,5)$ & --- & $91(37,4)$ & --- \\
\hline Moderately Active & $372(77,7)$ & $1.47(0.99-2.18)$ & $125(26,1)$ & --- & $150(31,3)$ & --- \\
\hline Active & $\begin{array}{c}174(72,2) \\
\text { p-value }=0,047\end{array}$ & $\begin{array}{c}1.00 \\
\text { p-value }=0,368^{*} \\
(79,6 \%)^{* *}\end{array}$ & $\begin{array}{c}71(29,5) \\
\text { p-value }=0,455\end{array}$ & --- & $\begin{array}{c}74(30,7) \\
\text { p-value }=0,113\end{array}$ & --- \\
\hline \multicolumn{7}{|l|}{ Leisure-time } \\
\hline Physically inactive & $189(82,9)$ & $1.43(0.90-2.28)$ & $85(37,3)$ & $1.82(1.22-2.71)$ & $93(40,8)$ & $1.82(1.25-2.66)$ \\
\hline Moderately Active & $310(77,1)$ & $1.13(0.78-1.64)$ & $118(29,4)$ & $1.35(0.95-1.92)$ & $137(34,1)$ & $1.41(1.01-1.96)$ \\
\hline Active & $\begin{array}{c}241(72,4) \\
\text { p-value }=0,004\end{array}$ & $\begin{array}{c}1.00 \\
\text { p-value }=0,843^{*} \\
(78,3 \%)^{* *}\end{array}$ & $\begin{array}{c}72(21,6) \\
\text { p-value }=0,001\end{array}$ & $\begin{array}{c}1.00 \\
\text { p-value }=0,253^{*} \\
(71,8 \%)^{* *}\end{array}$ & $\begin{array}{c}85(25,5) \\
\text { p-value }=0,001\end{array}$ & $\begin{array}{c}1.00 \\
\text { p-value }=0,894^{*} \\
(67,9 \%)^{* *}\end{array}$ \\
\hline
\end{tabular}

Notes: OR = odds ratio; 95\% CI = confidence interval of 95\%; ${ }^{*}=$ Hosmer-Lemeshow; ${ }^{* *}=$ Percentage of how much the model can explain the behavior of the outcome; Models adjusted simultaneously for: BHU, sex, age, smoking, economic status, SBP, DBP, BMI and WC.

In the multivariate-adjusted model, it was possible to detect that participants with lower level of PA in leisure-time had a higher occurrence of $\mathrm{DM}(\mathrm{OR}=1.79[1.17-2.72])$ and hypercholesterolemia $(\mathrm{OR}=1.85[1.24-2.76])$ (Table 2 ), independent of sport practice and occupational domain.

Finally, Table 3 has indicated that among participants with the lowest percentile of PA in leisure-time domain the occurrence of MetS was higher even after adjustments $(\mathrm{OR}=1.48$ [1.082.05]).

\section{Discussion}

This study aimed to examine associations between the occurrence of risk factors for MetS / MetS itself and physical inactivity in different domains among adults users of the public healthcare system in Brazil and found high rates of hypertension, DM, hypercholesterolemia, abdominal obesity and MetS, which were also associated with lower levels of PA.

The prevalence rates of chronic diseases found in our study were higher than those found in other national studies. In our sample, $76.8 \%$ of the participants were diagnosed with $\mathrm{AH}, 28.5 \%$ with DM, and $32.7 \%$ with hypercholesterolemia. Brazilian research assessing adults by telephone survey found that the frequency of self-reported $\mathrm{AH}$ was $52.1 \%$ for the age group of 55-64 years and $61.1 \%$ for the elderly ${ }^{17}$. Regarding DM, recent and nationally representative data on adults show an increased rate of $3.3 \%$ in 1998 to $5.3 \%$ in $2008^{18}$. Relating to hypercholesterolemia, Nascimento $\mathrm{Neto}^{19}$ found that $21.6 \%$ of the general population showed altered cholesterol levels, being 30\% among those with 45 years old or more. The three diseases have common risk indicators, such as smoking habits, physical inactivity, unhealthy diet and harmful use of alcohol. In addition, the current epidemic of obesity and the increased access to diagnostic tests are factors that explain most of this increase ${ }^{20}$.

The reason for the high prevalence rates of these diseases in our study may partly be explained by the fact that the sample is composed of patients of BHU, sites with high concentration of people with different chronic diseases. In connection with these results, the increased percentage of the population affected by chronic diseases could be better controlled if there were efficient programs related to health education, 
Table 2. Multivariate association between physical activity domains and chronic diseases (Brazil, $\mathrm{n}=963$ ).

\begin{tabular}{lccc}
\hline \multicolumn{1}{c}{ Domains } & $\begin{array}{c}\text { Arterial Hypertension } \\
\text { OR }(\mathbf{9 5 \%} \mathbf{C I})\end{array}$ & $\begin{array}{c}\text { Diabetes mellitus } \\
\text { OR }(\mathbf{9 5} \% \mathbf{C I})\end{array}$ & $\begin{array}{c}\text { Hypercholesterolemia } \\
\text { OR }(\mathbf{9 5} \% \mathbf{C I})\end{array}$ \\
\hline $\begin{array}{l}\text { Occupational } \\
\text { Physically inactive }\end{array}$ & $0.98(0.54-1.78)$ & $1.07(0.65-1.78)$ & $0.69(0.42-1.13)$ \\
$\begin{array}{l}\text { Moderately Active } \\
\text { Active }\end{array}$ & $0.68(0.44-1.05)$ & $0.86(0.58-1.26)$ & $1.13(0.79-1.61)$ \\
$\begin{array}{l}\text { Sports } \\
\text { Physically inactive }\end{array}$ & 1.00 & 1.00 & 1.00 \\
Moderately Active & $1.58(0.96-2.60)$ & $0.95(0.61-1.47)$ & $1.29(0.85-1.96)$ \\
Active & $1.41(0.94-2.11)$ & $0.77(0.53-1.12)$ & $0.91(0.63-1.29)$ \\
Leisure-time & 1.00 & 1.00 & 1.00 \\
Physically inactive & $1.20(0.74-1.97)$ & $1.79(1.17-2.72)$ & $1.85(1.24-2.76)$ \\
Moderately Active & $1.05(0.72-1.54)$ & $1.37(0.95-1.95)$ & $1.42(1.02-1.99)$ \\
Active & 1.00 & 1.00 & 1.00 \\
& p-value $=0,927^{*}(79,7 \%)^{* *}$ & p-value $=0,817^{*}(71,4 \%)^{* *}$ & p-value $=0,532^{*}(69 \%)^{* *}$ \\
\end{tabular}

Notes: OR = odds ratio; $95 \% \mathrm{CI}=$ confidence interval of $95 \%{ }^{*}{ }^{*}=$ Hosmer-Lemeshow; ${ }^{* *}=$ Percentage of how much the model can explain the behavior of the outcome; Models including three domains of physical activity simultaneously and adjusted for: BHU, sex, age, smoking, economic status, SBP, DBP, BMI and WC.

where strategies for food adequacy and changes in lifestyle could make a difference in preventing future complications and comorbidities, as well as the prospect of minimal economic impact to the health sector ${ }^{21}$.

Another important finding was the association between the occurrence of $\mathrm{AH}, \mathrm{DM}$ and hypercholesterolemia with indicators of general and abdominal obesity, information extensively observed in Brazilian and worldwide research$\mathrm{es}^{22-25}$. In developing countries improving economy and social situation, there is an increase in prevalence rates of obesity and factors associated with MetS, and the main causes of this dangerous association are increasing urbanization, nutrition transition, insufficient PA and the easiness of access to and supply of goods and services ${ }^{26}$.

Another particular finding was the association between lower levels of PA in different domains and the diseases analyzed. After adjustment for potential confounders, lower level of PA in leisure-time was significantly associated with a higher prevalence of DM, hypercholesterolemia and MetS, while the lowest level of sports practice was associated with increased prevalence of $\mathrm{AH}$.

These results are in accordance with Brazilian investigation, which found that physical inactivity was associated with the occurrence of $\mathrm{AH}$, hypercholesterolemia, obesity and clustering of chronic diseases, especially among men ${ }^{27}$. Furthermore, relevant research conducted by Lee et al. $^{28}$, which sought to evaluate the impact of
Table 3. Multivariate association between physical activity domains and metabolic syndrome (Brazil, $\mathrm{n}=963)$.

\begin{tabular}{lrc}
\hline \multicolumn{1}{c}{ Domains } & $\begin{array}{r}\text { Chi square } \\
\text { N (\%) }\end{array}$ & $\begin{array}{c}\text { Logistic Regression } \\
\text { OR }(\mathbf{9 5 \%} \text { CI })^{\S}\end{array}$ \\
\hline Occupational & & \\
Physically inactive & $79(32.9)$ & --- \\
Moderately Active & $166(34.5)$ & --- \\
Active & $79(32.6)$ & --- \\
p-value & 0.948 & \\
Sports & & --- \\
Physically inactive & $85(35)$ & --- \\
Moderately Active & $161(33.6)$ & --- \\
Active & $78(32.4)$ & \\
p-value & 0.543 & \\
Leisure-time & & \\
Physically inactive & $85(37.3)$ & $\mathbf{1 . 4 8}(\mathbf{1 . 0 8}$ to $\mathbf{2 . 0 5})$ \\
Moderately Active & $148(36.8)$ & $\mathbf{1 . 5 6}(\mathbf{1 . 0 6}$ to 2.29$)$ \\
Active & $91(27.3)$ & 1.00 \\
p-value & $\mathbf{0 . 0 0 8}$ & p-valor $=0,183^{*}$ \\
Overall & & \\
Physically inactive & $78(32.9)$ & --- \\
Moderately Active & $170(35)$ & --- \\
Active & $76(31.7)$ & --- \\
p-value & 0.771 & \\
\hline
\end{tabular}

Notes: OR = odds ratio; $95 \% \mathrm{CI}=$ confidence interval of $95 \%$; ${ }^{*}=$ Hosmer-Lemeshow; ${ }^{\S}=$ Model adjusted simultaneously for: BHU, sex, age, smoking, economic status, sports practice and occupational PA.

physical inactivity on major chronic diseases in the world, found that such behavior is responsi- 
ble for $7 \%$ of DM cases and 6\% of heart disease, in addition to increased mortality rates and decreased life expectancy.

Regarding to MetS, recently published meta-analysis showed that individuals with higher indicators of PA during leisure-time were 20\% less likely to develop the syndrome compared to those with lower involvement in this domain of $\mathrm{PA}^{29}$. Additionally, Najafian et al. ${ }^{30}$ found association between lower levels of PA and the occurrence of the MetS, as well as to inverse relationship between duration of daily walking and MetS.

Exploring the idea that exercise practice may confer tangible benefits for the prevention and reversal of risk factors for MetS, studies with different protocols and intensity of exercises have been undertaken in recent years. Randomized controlled trial with adults found reduction of indicators that cause the MetS, as well as reduction in visceral fat after one year of intervention with high intensity exercises ${ }^{31}$. Additionally, Colombo et al. ${ }^{32}$ found significant improvements in WC, BMI, SBP, DBP, and HDL-cholesterol in patients with MetS after twelve weeks of aerobic exercise program with moderate intensity.

\section{Collaborations}

BC Turi worked collecting data, interpretation of results and paper writing; JS Codogno worked collecting data, interpretation of results and revising paper; RA Fernandes assisted with statistical analysis, interpretation of results and revising paper; HL Monteiro guided the research project, analysis and interpretation of results and final revision of the paper.
Thus, population ageing and rates of obesity increasing lead to key questions: Can PA attenuates the weight gain associated with aging? Can PA prevent the occurrence of metabolic diseases in adults? Current guidelines recommend a daily of 60 minutes of moderate-intensity PA, plus at least two sessions per week of resistance training to ensure substantial and additional health benefits and weight loss ${ }^{33}$. Therefore, evidence suggests that promotion of energy balance, changes in the distribution of body fat and increased muscle mass can to result in better metabolic control ${ }^{34}$.

As limitation we have the cross-sectional design that does not allow cause-effect conclusions. In fact, a cohort study has been conducted with this sample and, in the future, it will be possible ratify or not our findings in a longitudinal design.

In conclusion, the present study found high rates of risk factors associated to MetS, as well as for MetS itself and chronic diseases as AH, DM, hypercholesterolemia, and obesity. Furthermore, there was association between lower engagement in PA during leisure-time and higher occurrence of risk factors for MetS.

\section{Acknowledgments}

The Brazilian Federal Agency for Support and Evaluation of Graduate Education - CAPES. 


\section{References}

1. Alberti KG, Eckel RH, Grundy SM, Zimmet PZ, Cleeman JI, Donato KA, Fruchart JC, James WP, Loria CM, Smith SC Jr; International Diabetes Federation Task Force on Epidemiology and Prevention; Hational Heart, Lung, and Blood Institute; American Heart Association; World Heart Federation; International Atherosclerosis Society; International Association for the Study of Obesity. Harmonizing the metabolic syndrome: a joint interim statement of the International Diabetes Federation Task Force on Epidemiology and Prevention; National Heart, Lung, and Blood Institute; American Heart Association; World Heart Federation; International Atherosclerosis Society; and international association for the Study of Obesity. Circulation 2009; 120(6):1640-1645.

2. Wilson PW, D'Agostino RB, Parise H, Sullivan L, Meigs JB. Metabolic syndrome as a precursor of cardiovascular disease and type 2 diabetes mellitus. Circulation 112, 3066-3072, 2005.

3. Kolovou GD, Anagnostopoulou KK, Salpea KD, Mikhailidis DP. The prevalence of metabolic syndrome in various populations. Am J Med Sci 2007; 333(6):362371.

4. International diabetes federation (IDF). The IDF consensus worldwide definition of the metabolic syndrome. Brussels: IDF; 2006

5. Silveira VM, Horta BL, Gigante DP, Azevedo Junior MR. Metabolic syndrome in the 1982 Pelotas cohort: effect of contemporary lifestyle and socioeconomic status. Arq Bras Endocrinol Metabol 2010; 54(4):390397.

6. Barbieri MA, Bettiol H, Silva AA, Cardoso VC, Simoes VM, Gutierrez MR, Castro JA, Vianna ES, Foss MC, Dos Santos JE, Queiroz RG. Health in early adulthood: the contribution of the 1978/79 Ribeirao Preto birth cohort. Braz J Med Biol Res 2006; 39(8):1041-1055.

7. Zhang JH, Li NF, Yan ZT, Zhang L, Wang HM, Guo YY Ling Z. Association of genetic variations of PRDM16 with metabolic syndrome in a general Xinjiang Uygur population. Endocrine 2012; 41(3):539-541.

8. Yang $\mathrm{T}$, Chu $\mathrm{CH}$, Hsieh $\mathrm{PC}, \mathrm{Hsu} \mathrm{CH}$, Chou YC, Yang $\mathrm{SH}$, Bai CH, You SL, Hwang LC, Chung TC, Sun CA. $\mathrm{C}$-reactive protein concentration as a significant correlate for metabolic syndrome: a Chinese population-based study. Endocrine 2013; 43(2):351-359.

9. Tsai $\mathrm{CH}, \mathrm{Li} \mathrm{TC}$, Lin CC, Tsay HS. Factor analysis of modifiable cardiovascular risk factors and prevalence of metabolic syndrome in adult Taiwanese. Endocrine 2011; 40(2):256-264.

10. Lakka TA, Laaksonen DE. Physical activity in prevention and treatment of the metabolic syndrome. Appl Physiol Nutr Metab 2007; 32(1):76-88.

11. Kilsztajn S, Rossbach A, Câmara MB, Carmo MSN. Serviços de saúde, gastos e envelhecimento da população brasileira. Rev Bras Estud Popul 2003; 20(1):93-108.

12. Baecke JAH, Burema J, Frijters JER. A short questionnaire for the measurement of habitual physical activity in epidemiological studies. Am J Clin Nutr 1982; 36(5):936-942.

13. Codogno JS, Fernandes RA, Sarti FM, Freitas Junior IF, Monteiro HL. The burden of physical activity on type 2 diabetes public healthcare expenditures among adults: a retrospective study. BMC Public Health 2011; 11:275.
14. Associação Brasileira de Empresas de Pesquisa. Dados com base no Levantamento Sócio Econômico 2008 IBOPE, 2010. [cited March 10 $0^{\text {th }}, 2010$ ]. Available at: www.abep.com.br

15. Peixoto MRG, Benício MHD, Latorre MRDO, Jardim PCBV. Circunferência da cintura e índice de massa corporal como preditores da hipertensão arterial. Arq bras cardiol 2006; 87(4):462-470.

16. World Health Organization (WHO). Obesity, Preventing and Managing the Global Epidemic: Report of the WHO Consultation on Obesity. Geneva: WHO; 1998. [cited April 16 $\left.6^{\text {th }}, 2010\right]$. Available at: http://www.who. int/nutrition/publications/obesity_executive_summary.pdf

17. Perez LG, Pratt M, Simoes EJ, de Moura L, Malta DC. Association between leisure-time physical activity and self-reported hypertension among Brazilian adults, 2008. Prev Chronic Dis 2013; 10:E172.

18. Viacava F. Acesso e uso de serviços de saúde pelos brasileiros, 2010. [cited June 29 $9^{\text {th }}, 2014$ ]. Available at: http:// www4.ensp.fiocruz.br/radis/96/pdf/radis_96.pdf

19. Nascimento Neto RM. Atlas Corações do Brasil. 2010. [cited June 27 $7^{\text {th }}, 2014$ ]. Available at: http://www.saude. sp.gov.br/resources/profissional/acesso_rapido/gtae/ saude_pessoa_idosa/atlas_190_1.pdf

20. Schmidt MI, Duncan BB, Azevedo e Silva G, Menezes AM, Monteiro CA, Barreto SM, Chor D, Menezes PR. Chronic non-communicable diseases in Brazil: burden and current challenges. Lancet 2011; 377(9781):19491961.

21. Monteiro CA, Moura EC, Jaime PC, Lucca A, Florindo AA, Figueiredo ICR, Bernal R, Silva NN. Monitoramento de fatores de risco para doenças crônicas por entrevistas telefônicas. Rev Saude Publica 2005; 39(1):47-57

22. Lloyd-Sherlock P, Beard J, Minicuci N, Ebrahim S, Chatterji S. Hypertension among older adults in lowand middle-income countries: prevalence, awareness and control. Int J Epidemiol 2014; 43(1):116-128.

23. Klop B, Elte JW, Cabezas MC. Dyslipidemia in obesity: mechanisms and potential targets. Nutrients 2013; 5(4):1218-1240.

24. Schmidt MI, Duncan BB, Hoffmann JF, Moura Ld, Malta DC, Carvalho RM. Prevalence of diabetes and hypertension based on self-reported morbidity survey, Brazil, 2006. Rev Saude Publica 2009; 43(Supl. 2):74-82.

25. Kahn SE, Hull RL, Utzschneider KM. Mechanisms linking obesity to insulin resistance and type 2 diabetes. Nature 2006; 444(7121):840-846.

26. Misra A, Khurana L. Obesity and the metabolic syndrome in developing countries. J Clin Endocrinol Metab 2008; 93(11 Supl. 1):S9-30.

27. Garcia L MT, Silva KS, Del Duca GF, Costa FF, Nahas MV. Sedentary Behaviors, Leisure-Time Physical Inactivity, and Chronic Diseases in Brazilian Workers: A Cross Sectional Study. J Phys Act Health 2014; 11(8):1622-1634.

28. Lee IM, Shiroma EJ, Lobelo F, Puska P, Blair SN, Katzmarzyk PT; Lancet Physical Activity Series Working Group. Effect of physical inactivity on major non-communicable diseases worldwide: an analysis of burden of disease and life expectancy. Lancet 2012; 380(9838):219-229. 
29. He D, Xi B, Xue J, Huai P, Zhang M, Li J. Association between leisure time physical activity and metabolic syndrome: a meta-analysis of prospective cohort studies. Endocrine 2013; 46(2):231-240.

30. Najafian J, Mohammadifard N, Naeini FF, Nouri F. Relation between usual daily walking time and metabolic syndrome. Niger Med J 2014; 55(1):29-33.

31. Dutheil F, Lac G, Lesourd B, Chapier R, Walther G, Vinet A, Sapin V, Verney J, Ouchchane L, Duclos M, Obert P, Courteix D. Different modalities of exercise to reduce visceral fat mass and cardiovascular risk in metabolic syndrome: the RESOLVE randomized trial. Int J Cardiol 2013; 168(4):3634-3642.

32. Colombo CM, Macedo RM, Fernandes-Silva MM, Caporal AM, Stinghen AE, Costantini CR, Baena CP, Guarita-Souza LC, Faria-Neto JR. Short-term effects of moderate intensity physical activity in patients with metabolic syndrome. Einstein (São Paulo) 2013; 11(3):324-330.

33. Grundy SM, Hansen B, Smith Junior SC, Cleeman JI, Kahn RA. American Heart Association; National Heart, Lung, and Blood Institute; American Diabetes Association. Clinical management of metabolic syndrome: report of the American Heart Association/National Heart, Lung, and Blood Institute/American Diabetes Association conference on scientific issues related to management. Circulation 2004; 109(4):551-556

34. Strasser B. Physical activity in obesity and metabolic syndrome. Ann N Y Acad Sci 2013; 1281:141-159.

Artigo apresentado em 19/04/2015

Aprovado em 27/11/2015

Versão final apresentada em 29/11/2015 